\title{
LA CAMPAÑA DE INCENDIOS DE 2006 EN GALICIA: UN ANÁLISIS DEL CAMBIO EN LA DISTRIBUCIÓN ESPACIAL DE LAACTIVIDAD INCENDIARIA
}

\author{
José Balsa-Barreiroํㅜ, Txomin Hermosilla² y Rubén C. Lois González ${ }^{3}$ \\ ${ }^{1}$ Departamento de Métodos Matemáticos e de Representación \\ Universidade da Coruña \\ jose.balsa.barreiro@udc.es \\ ${ }^{2}$ Integrated Remote Sensing Studio \\ University of British Columbia \\ txomin.hermosilla@live.forestry.ubc.ca \\ ${ }^{3}$ Departamento de Xeografía \\ Universidade de Santiago de Compostela \\ rubencamilo.lois@usc.es
}

\section{RESUMEN}

El presente estudio pretende analizar la importancia del análisis geográfico y de los recursos cartográficos en el conocimiento de hechos catastróficos. Los incendios forestales son una plaga recurrente en Galicia. La evolución histórica muestra un incremento continuo de los fuegos hasta los años 1990, momento en que su enorme capacidad destructora ha comenzado a ser moderada. Sus causas y efectos han sido explicados en numerosos estudios. En las siguientes páginas se determinará cómo los patrones espaciales de la campaña incendiaria de 2006 fueron distintos a los de los cinco años anteriores. Y cómo el análisis geográfico y cartográfico constituyen instrumentos muy útiles para medir los cambios registrados.

Palabras clave: incendio forestal, Galicia, monte, abandono rural, distribución espacial.

\section{ABSTRACT}

This study analyzes the importance of geography and map resources in the knowledge of catastrophic events. Forest fires are a recurrent plague in Galicia. The historical evolution shows a continuous increase until the 1990 fire, when its enormous destructive power has begun to be moderate. Its causes and effects have been explained in numerous studies. Here

Fecha de recepción: febrero 2012.

Fecha de aceptación: enero 2013. 
we are focus in determining the reasons of the different the spatial patterns exhibited by the wildfires occurred in 2006. And as the geographic analysis and mapping are useful tools to measure changes.

Keywords: wildfire, Galicia, mountain, rural neglect, spatial distribution.

\section{INTRODUCCIÓN}

El sector forestal gallego, a pesar de su gran significación productiva, presenta una serie de problemas coyunturales y estructurales (Sineiro, 2005). Entre estos últimos podemos destacar la cuestión de la propiedad, la escasa profesionalización del sector, una explotación basada en criterios productivistas y cortoplacistas, la escasa puesta en valor de las tierras de monte, la ausencia de políticas adecuadas por parte de la administración, etc. (Marey et al., 2004; Ambrosio et al., 2001). Todo ello conduce a un modelo forestal de gestión deficiente (Balsa-Barreiro, 2012a), que se manifiesta en un crecimiento desordenado del monte.

Los incendios en Galicia son un síntoma claro de este modelo deficiente de aprovechamiento forestal, siendo relativamente frecuente la aparición cíclica de graves crisis en las que el fuego arrasa miles de hectáreas (Negreira del Río, 2004). Estas crisis incendiarias, percibidas frecuentemente por la sociedad como episodios trágicos aislados, son más bien la punta del iceberg del grave problema derivado de una ineficiente gestión continuada del monte gallego desde mediados del siglo XX.

Muchos autores coinciden en afirmar la existencia de una serie de factores territoriales negativos, tales como la desestructuración sociodemográfica de Galicia (entre diversos ámbitos geográficos y entre zonas rurales y urbanas) y la ausencia de un modelo de ordenación territorial equilibrado (Balsa-Barreiro, 2012a), que sin duda adquieren una gran influencia sobre los principios seguidos en la gestión forestal. Desde hace años existe un amplio debate acerca del papel que cumple la superficie forestal en Galicia (Lage, 2002 y 2003; Rigueiro y Mosquera, 2005; Sineiro, 2005) y el análisis del grado de influencia que éste tiene sobre el origen del fuego, la propagación de los incendios y sus consecuencias finales.

El origen de los incendios (casi la totalidad son intencionados según la Consellería de Medio Rural, 2007) está relacionado con una serie de colectivos con intereses particulares. El propio descontento de alguno de estos grupos y las expectativas especuladoras de otros repercuten en la gestión real del monte y en la aparición de crisis incendiarias recurrentes.

La crisis incendiaria del verano de 2006 fue la más trágica vivida por Galicia en los últimos años, y tuvo unas nefastas consecuencias, tanto humanas como económicas. Además de cobrarse la vida de cuatro personas, supuso un coste económico de entre 248 y 336 millones de , lo que supone aproximadamente entre el 0,62 y el 0,84\% del PIB de Galicia según el estudio de Loureiro y Barrio (2009), en el que sólo se hace un análisis de los costes a corto plazo y se excluyen una serie de variables de difícil cuantificación.

El carácter excepcional de la campaña incendiaria del año 2006 lo fue, no solamente por su magnitud sino también por una nueva tipología de incendios, muy diferente a la de los años anteriores. Una de las características más representativas de esa campaña fue que la mayor parte de la actividad incendiaria se concentró en áreas periurbanas próximas a la 
principal arteria económica y demográfica de Galicia. Se produjo así un cambio respecto a la distribución espacial habitual de los incendios, que afecta principalmente a los en pequeños municipios rurales de la mitad meridional.

La enorme magnitud de los incendios de 2006 se debió a este cambio en el patrón espacial, el cual sorprendió a los medios de extinción y a las autoridades competentes, mostrándose incapaces de articular una respuesta adecuada (Martínez, 2007 y 2008) ante esta nueva dinámica. En esta nueva situación existen una serie de factores espaciales de gran importancia tales como la gran concentración espacio-temporal de los incendios, la cercanía a los núcleos de población o la proximidad a enclaves turísticos de gran valor paisajístico, etc. Estos factores explicarían el fracaso de los sistemas de extinción, que se vieron desbordados debido a la mayor vulnerabilidad derivada de la cercanía de los incendios a las vías de comunicación, principales lugares turísticos y núcleos habitados en general. Se produjo así un fenómeno de retroalimentación del fuego de nefastas consecuencias, que conllevó grandes pérdidas materiales y obligó a llevar a cabo más desalojos, lo que acabaría proyectando al exterior una imagen de caos y deficiente actuación política.

\section{OBJETIVO Y METODOLOGÍA}

En este artículo se propone analizar la tipología de la actividad incendiaria en Galicia durante el año 2006. Para ello se estudia la dinámica seguida por el fuego y su patrón de distribución espacial, comparándola con la situación habitual de años precedentes. Posteriormente se analizan una serie de variables y se contrastan con una serie normal, con objeto de evaluar cuál fue la magnitud real de la tragedia y que nivel de excepcionalidad presentó.

Primeramente se lleva a cabo una contextualización de la actividad incendiaria en Galicia desde el último tercio del siglo XX hasta el año 2006. De esta forma se puede observar el nivel de frecuencia de aparición de crisis recurrentes y de carácter cíclico. De ahí se pasa a analizar de forma concreta la magnitud de la campaña incendiaria del año 2006. Empleamos una serie de variables y parámetros estadísticos relacionados tanto con el número de incendios como con el volumen de superficie forestal arrasada a partir de un estudio retrospectivo para el que se considera una serie temporal lo suficientemente larga (entre los años 2001 y 2005). A partir de esta serie temporal se pueden extraer un conjunto de parámetros medios de lo ocurrido en situaciones habituales. En nuestro caso se compara directamente la campaña del 2006 con los cinco años precedentes que conforman nuestra serie temporal habitual con objeto de evaluar de forma clara la magnitud real de la oleada incendiaria de 2006.

\section{EL PROBLEMA DE LOS INCENDIOS FORESTALES EN GALICIA. LA CRISIS INCENDIARIA DE 2006.}

Los incendios forestales en Galicia son un signo y/o síntoma de un traumático y conflictivo cambio en la organización de los usos del suelo debido a una serie de importantes procesos demográficos y a la crisis del sistema agrario tradicional. El fuerte éxodo rural vivido en Galicia desde la segunda mitad del siglo XX, unido a un régimen de propiedad ineficiente (por lo general, privada, que simplemente retiene pequeñas parcelas con fines especulativos, pues el monte en mano común arde menos), ha provocado que una buena parte de la super- 
ficie forestal de Galicia crezca de forma desordenada como monte, entendido éste como el «terreno inculto en un cierto estado de abandono debido a una ausencia tradicional de cuidados culturales y de cultivos agrícolas» (Lage, 2003).

Galicia, a pesar de tan sólo suponer el 5,9\% de la población española y del 5,8\% de su superficie (INE, 2010), es la región más afectada por los incendios de toda España (Bardaji y Molina, 1999; Baamonde, 2005) y prueba de ello es que durante la última década en torno a un $50 \%$ de la superficie quemada y a un $35 \%$ del número de incendios a nivel nacional han tenido lugar aquí. Sólo en el período 1995-2005 Galicia ha perdido un 17,6\% de toda su superficie forestal a causa de los incendios forestales (Hernández, 2006).

La serie histórica desde que tenemos datos hasta la última gran oleada incendiaria, correspondiente a los años 1968-2006 -gráfico 1 -permite distinguir varios aspectos de interés:

- La tendencia ascendente continuada, en diente de sierra, del número de incendios hasta el año 1995 (máximo absoluto con 15.218) y la tendencia descendente desde ese año, también fluctuante y de carácter más estabilizado.

- El total de superficie forestal afectada por la crisis incendiaria de 2006 es muy alto en relación con los años precedentes, aunque es considerablemente menor que el propio de otras grandes crisis como las de 1978, 1981, 1985 y 1989. DE INCENDIOS

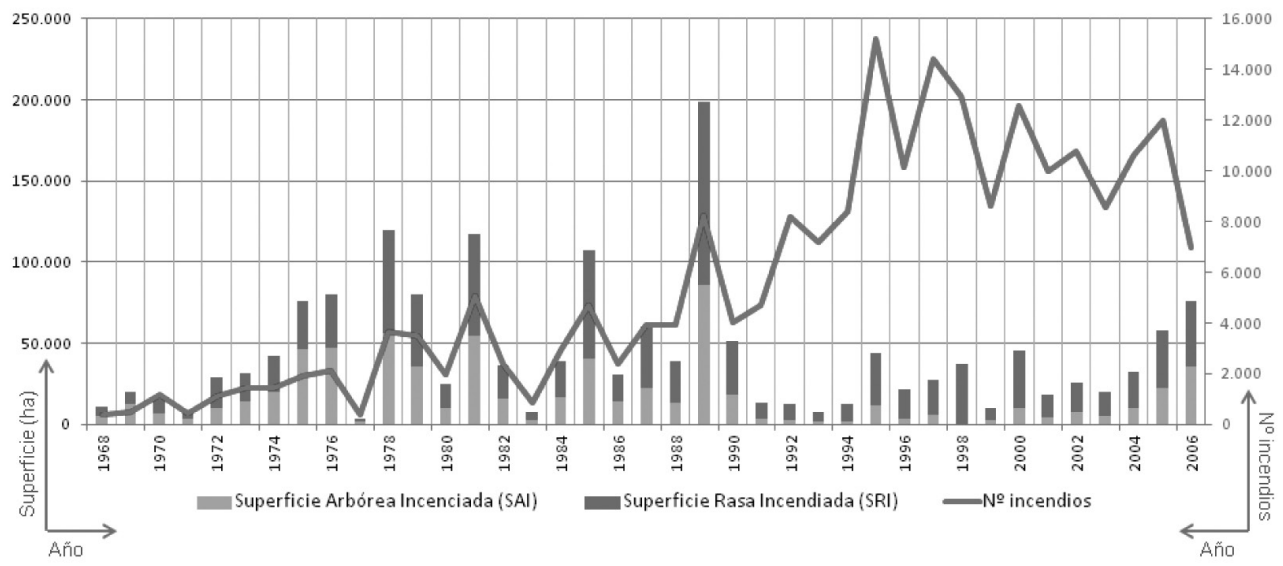

Fuente: Dirección Xeral de Montes e Industrias Forestais, Consellería de Medio Ambiente, 2007.

En los últimos años se observa una tendencia continuada hacia una reducción muy clara de la superficie media afectada por incendio, a pesar del máximo relativo que supone la crisis de 2006. Con objeto de ir más allá en nuestro análisis, calculamos un índice de eficacia propio (IE) de carácter anual a partir del cociente entre el número de incendios registrado y el total de superficie afectada. El índice calculado (IE) presenta dos fases diferentes a lo largo de la serie temporal -gráfico 2-: (a) una primera, hasta el año 1990, en la que los valores de este índice nunca son superiores a 10 y (b) una segunda, a partir de ese año, en la que sus 
valores se multiplican por varios enteros, dependiendo de las fluctuaciones anuales. El índice de eficacia calculado presenta un descenso muy brusco entre los años 2003 y 2006, llegando a alcanzar niveles similares a los propios de la primera fase.

Gráfico 2

REPRESENTACIÓN DE ÍNDICES REPRESENTATIVOS DE LAACTIVIDAD INCENDIARIA EN GALICIA ENTRE LOS AÑOS 1968 Y 2006

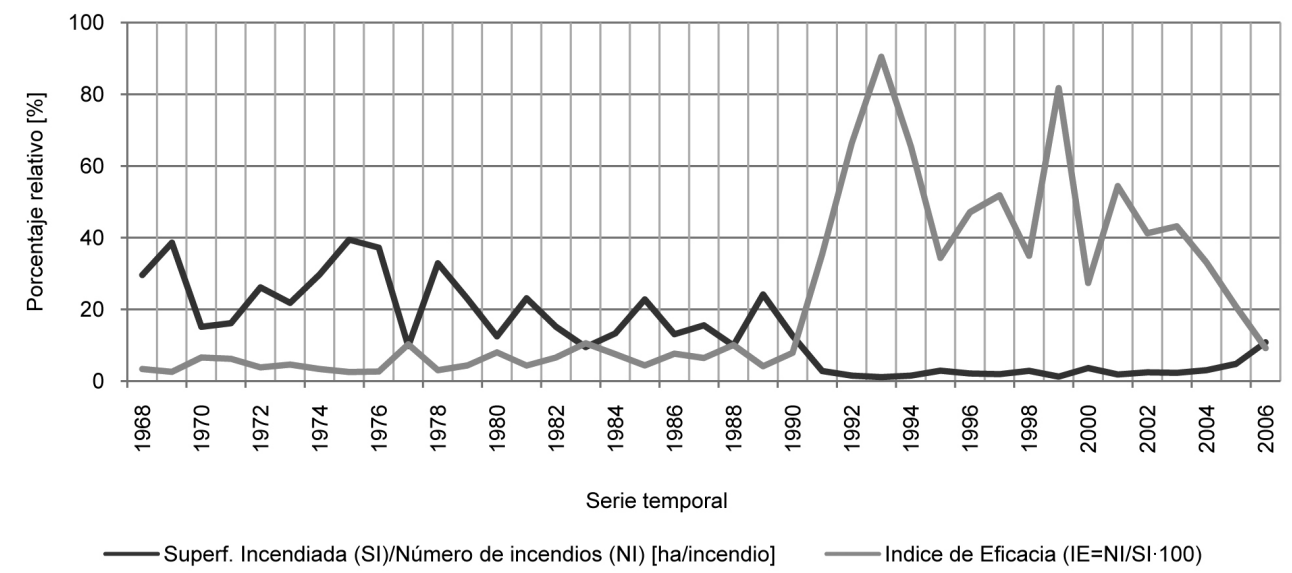

Fuente: Dirección Xeral de Montes e Industrias Forestais, Consellería de Medio Ambiente, 2007.

El aumento del IE se debe al incremento del numerador (número de incendios registrados) o al decremento del denominador (superficie afectada), aunque en el caso que aquí nos ocupa vemos claramente que lo que se ha producido ha sido una conjunción de ambos factores: más incendios y menos superficie incendiada. A la vista de los dos gráficos anteriores -1 y 2 - se pone de manifiesto la mejora lograda por los sistemas de extinción de incendios, que ha permitido reducir de forma muy considerable la superficie afectada, aunque también se aprecia el mal funcionamiento de los sistemas de prevención, lo que explicaría el fuerte incremento del número de incendios acaecidos desde principios de la década de 1990.

Entre los años 2001 y 2005 los incendios arrasaron más del 8\% superficie forestal de Galicia, un dato medio con una gran variabilidad entre las distintas provincias: Lugo con el 3,5\% fue la menos afectada y en el otro extremo, Ourense, con el 14\% la más afectada. Así, mientras en las dos provincias septentrionales este porcentaje no llegó al 6\%, en las dos meridionales fue superior al $10,5 \%$ de toda la superficie forestal.

La contraposición entre las dos provincias orientales, Lugo y Ourense, se debe a su diferente nivel de desarrollo agropecuario. De hecho, aunque ambas provincias presenten unas dinámicas demográficas claramente regresivas, con bajas densidades, altos niveles de población rural y fuertes procesos de envejecimiento poblacional, el desarrollo de una ganadería productivista en varias comarcas lucenses (Lois-González, 1995) supone una mayor interacción con el espacio forestal y un menor proceso de abandono que en Ourense. Además, una segunda causa es el factor climático que explicaría unas condiciones más secas en la provincia ourensana durante la época estival (Martí et al., 2011), lo 
que induciría a un mayor riesgo de incendio forestal, tanto en términos de origen como de propagación de incendios.

La campaña incendiaria de 2006 supuso una crisis cíclica importante. A ello contribuyó el alto grado de concentración espacial y temporal de los incendios. En sólo 12 días, entre el 3 y el 15 de agosto, resultaron calcinadas más hectáreas que durante todo el año anterior, siendo las dos provincias atlánticas las más damnificadas. Ese año se produjeron en Galicia casi 7.000 incendios en los que se quemaron unas 95.950 ha de superficie forestal, aunque las consecuencias más trágicas se dieron en las dos provincias occidentales, en las que resultaron arrasadas más de 35.000 ha en cada una de ellas, lo que supuso casi un $8 \%$ del total en el caso de A Coruña y de más de un 14\% en Pontevedra (Consellería de Medio Rural, 2007) -gráfico 3 y figura $1-$.

ACTIVIDAD INCENDIARIA EN CADA UNA DE LAS PROVINCIAS GALLEGAS PARA LAS DIFERENTES SERIES TEMPORALES

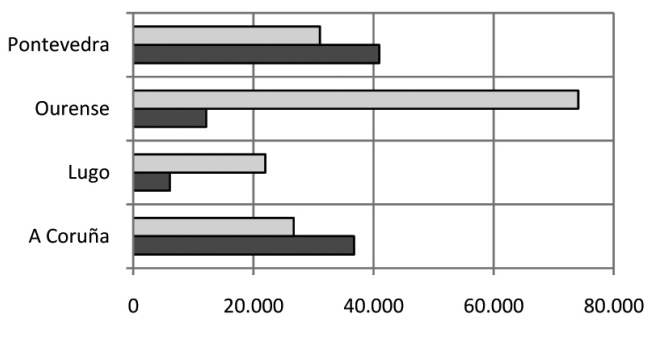

Superficie Forestal calcinada (ha)

口Total 2001-2005 प2006

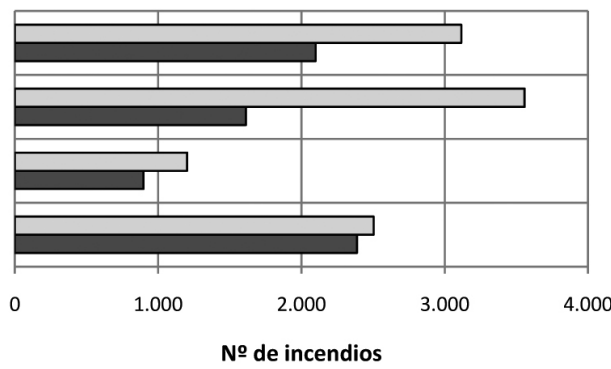

口2001-2005 (año promedio) प2006

Fuente de datos: Consellería de Medio Rural, 2007.

El diagrama Box and Whisker representado en el gráfico 4 muestrala incidencia de la actividad incendiaria (SFA en miles de ha) a nivel provincial en las distintas series temporales. Los outliers o valores anómalos individualizan municipios en los que la actividad incendiaria tuvo una incidencia muy superior a la del resto de su provincia. A nivel provincial, la mayor parte de outliers se registran tradicionalmente en Ourense, mientras que en el año 2006 pasan a concentrarse principalmenteen A Coruña y Pontevedra, presentando además un carácter más anómalo y/o extremo. Por su parte, la no coincidencia entre los valores media y mediana, junto a la poca representatividad de la «pestaña» izquierda en los respectivos diagramas, pone de manifiesto la asimetría en la distribución de la actividad incendiaria tanto entre las diferentes provincias (nivel interprovincial) como entre los diferentes municipios que forman parte de una misma provincia (nivel intraprovincial).

El incremento sustancial de superficie arrasada en 2006 contrasta, sin embargo, con la evolución del número de incendios -ver gráfico 3 y figura 1-, que sufre un descenso importante ese mismo año (6.999) respecto a los precedentes (promedio=10.380). Cabe preguntarse así el porqué en el año 2006 ardió mucho más el monte gallego (+65.188 ha respecto a la media de los otros años) si se produjeron muchos menos incendios ( -3.381 incendios de 


\section{Gráfico 4}

COMPARACIÓN DE LAACTIVIDAD INCENDIARIA EN CADA UNA DE LAS PROVINCIAS GALLEGAS PARA CADA SERIE TEMPORAL. LAS «PESTAÑAS» A LA IZQUIERDA Y DERECHA DE LA CAJA REPRESENTAN LOS CUARTILES EXTREMOS (Q1 Y Q4), MIENTRAS QUE DENTRO DE LA CAJA ESTARIAN LOS DOS CUARTILES CENTRALES (Q2 Y Q3), SEPARADOS ÚNICAMENTE POR UNA LÍNEA VERTICAL QUE DETERMINARIA EL VALOR MEDIANO. LA CRUZ DENTRO DE CADA CAJA REPRESENTA EL VALOR MEDIA. POR ÚLTIMO, LOS VALORES SUELTOS, SITUADOS EN ESTE CASO TODOS ELLOS A LA DERECHA DE LOS RESPECTIVOS DIAGRAMAS, REFLEJAN LA PRESENCIA DE VALORES ANÓMALOS (OUTLIERS), LOS CUALES ESTÁN FUERA DEL DOMINIO NORMAL DE LA MUESTRA
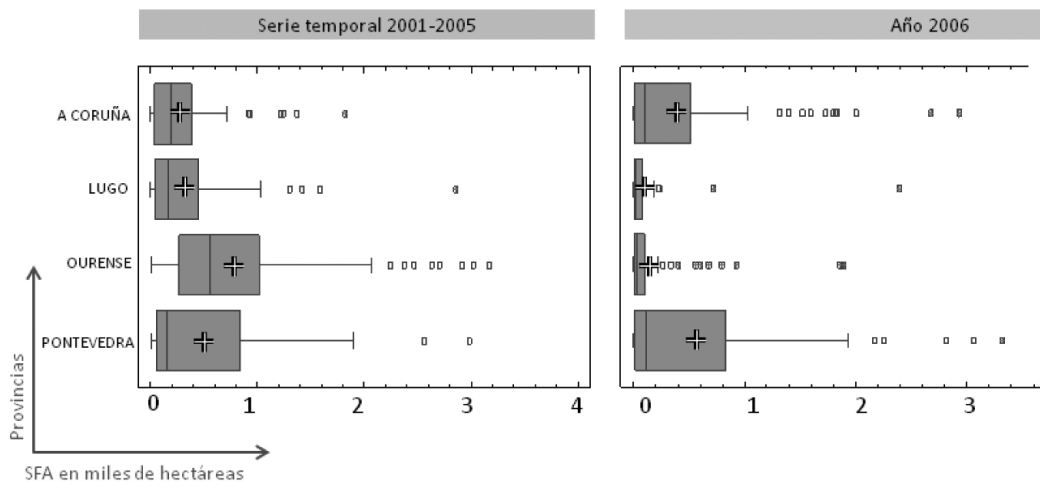

(...)

Fuente de datos: Consellería de Medio Rural, 2007.

Figura $1(1.1+1.2)$

ACTIVIDAD INCENDIARIA EN LAS PROVINCIAS GALLEGAS ENTRE LOS AÑOS 2001 Y 2006. DATOS RELATIVOS A LA SUPERFICIE FORESTAL AFECTADA (1.1) Y AL NÚMERO DE INCENDIOS (1.2). EL TAMAÑO DE LOS CÍRCULOS ES PROPORCIONAL AL SUMATORIO DE LA VARIABLE REPRESENTADA PARA EL CONJUNTO DE LA SERIE 2001-2006. EN COLOR ROJO SE REPRESENTA EL PESO RELATIVO DE LA CAMPAÑA DE 2006

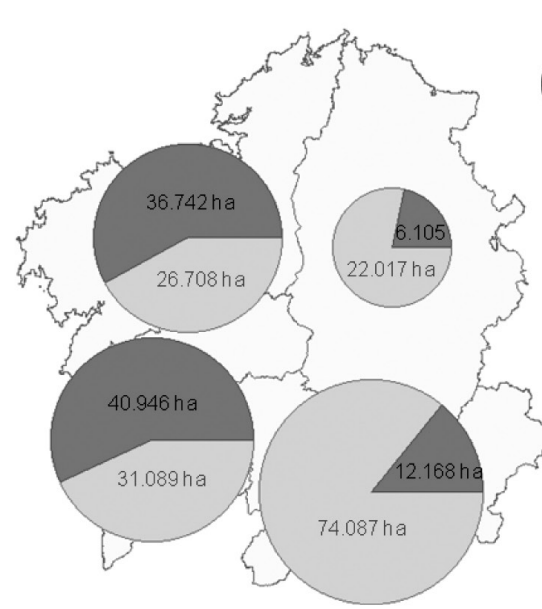

Superficie forestal afectada por los incendios [Datos en ha calcinadas]

$\begin{aligned} & \square \\ & \square\end{aligned}$ Serie temporal 2001-2005
A.ño 2006

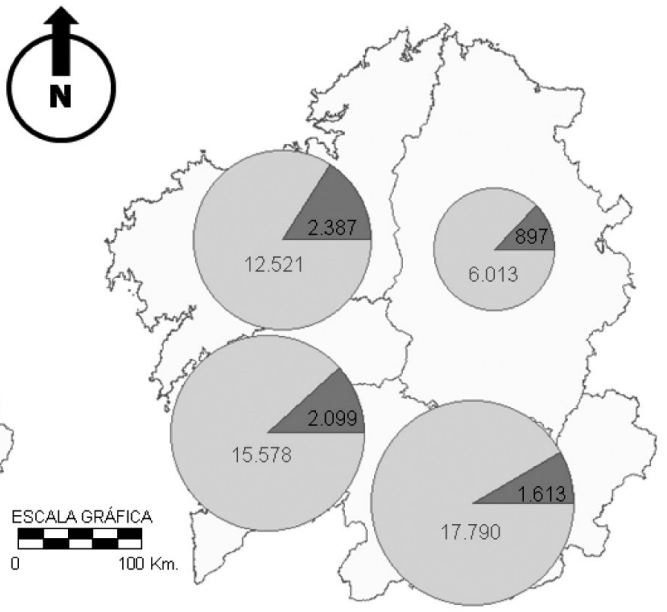

Número de incendios [Datosen $n^{\circ}$ ]

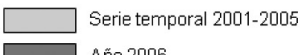

Fuente de datos: Consellería de Medio Rural, 2007. 
media). La respuesta se debe al cambio en el patrón espacial de la actividad incendiaria y a una serie de factores relacionados que indujeron a una rápida propagación y extensión del fuego en las dos provincias atlánticas. Entre dichos factores destacamos, por ejemplo, la presencia de unas condiciones naturales propicias (calor intenso y ausencia de precipitaciones), la gran concentración espacio-temporal de la actividad incendiaria y las insuficiencias que caracterizaron a los sistemas de prevención-extinción de incendios.

La oleada incendiaria de 2006 se concentró en unos 15 días en los que las condiciones naturales en general y meteorológicas en particular incrementaron exponencialmente el riesgo de incendios forestales. Entre las mismas podemos enumerar un conjunto a las que muchos autores aluden frecuentemente (Fernández-Couto, 2006; Chas y Montero, 2009): el fuerte déficit hídrico, las altas temperaturas, la baja humedad relativa, la presencia del viento Nordés, las condiciones edáficas propias de los suelos gallegos con una escasa capacidad de retención de agua, etc. Estos condicionantes, aunque existen y pueden llegar a tener una enorme relevancia, sobre todo en la fase de propagación, no justifican sin embargo por sí solos el cambio de patrón espacial ocurrido ese año.

Resulta pues interesante analizar la tipología de incendio forestal ocurrido ese año y compararlo con la del período precedente. El análisis del nivel de concentración de la actividad forestal a nivel municipal apunta a un cambio claro. En el gráfico 5 se representa un diagrama de Pareto en cuyo eje de abscisas aparecen indexados los municipios gallegos en sentido descendente en función de los parámetros señalados (sumatorio de la superficie forestal afectada y sumatorio del número de incendios para cada serie temporal), mientras

Gráfico 5

EVOLUCIÓN DE LAACTIVIDAD INCENDIARIA EN LOS MUNICIPIOS DE GALICIA PARA LAS DIFERENTES SERIES

TEMPORALES. CADA UNA DE LAS LÍNEAS REFLEJA EL PESO RELATIVO ACUMULADO DE CADA UNO DE LOS PARÁMETROS. INDEXACIÓN DE LOS MUNICIPIOS (HIGH-LOW) EN FUNCIÓN DE CADA UNO DE LOS PARÁMETROS ANALIZADOS ( $I$ INCENDIOS Y $\Sigma S F A)$

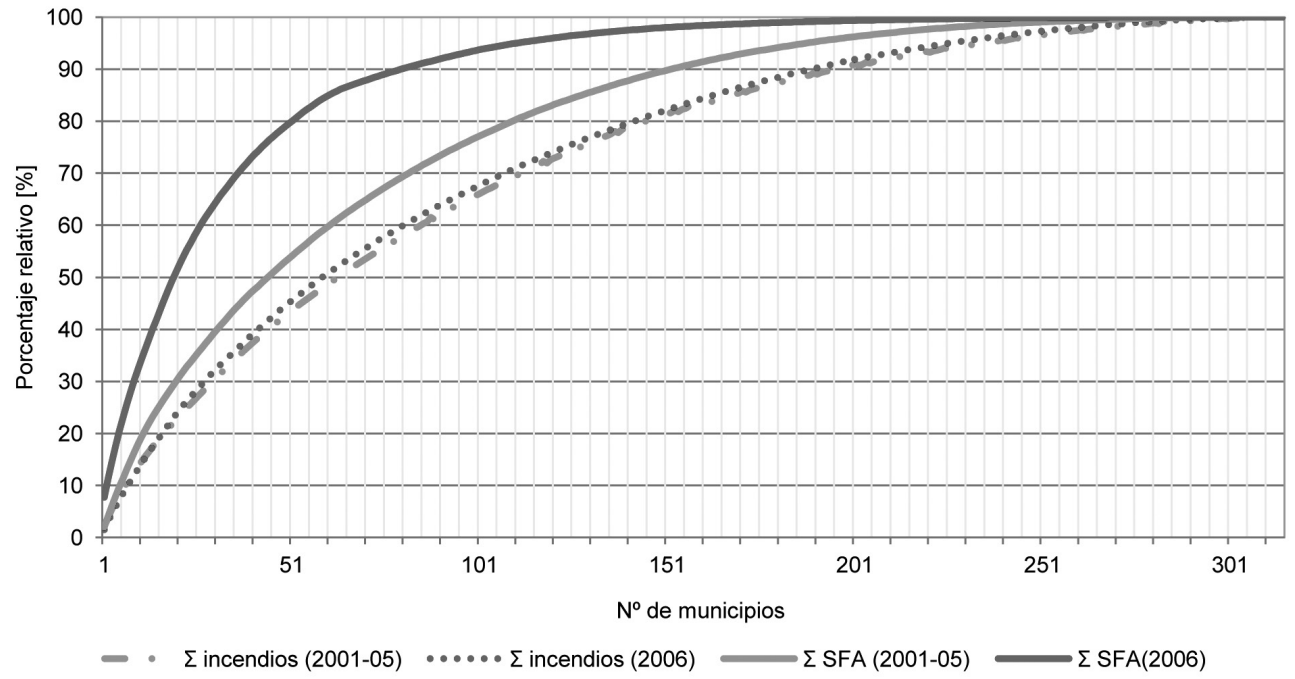

Fuente de datos: Consellería de Medio Rural, 2007. 
que el eje de ordenadas muestra el peso relativo respecto a la totalidad para cada parámetro. De esta forma observamos claramente cómo el patrón espacial ha variado, debido no a un cambio en el número de incendios y sí en el volumen de superficie forestal afectada. Así, el $85 \%$ de la superficie forestal afectada en la serie temporal 2001-2005 se concentraba en 129 municipios, mientras que en el año 2006 ese mismo porcentaje se concentraba en menos de la mitad (61 municipios).

Podemos conocer más de la tipología de incendio forestal de Galicia si la relacionamos, a escala municipal, con una serie de variables. Un análisis en función de la variable población de cada uno de los municipios permite establecer unos cuartiles (Q) a intervalos semejantes, que engloban un número similar de municipios. Los mismos se delimitan por unos valores de población determinados: Q1 (<1.910 habitantes) y Q2 (1.910-3.489), Q3 (3.490-6.896) y Q4 (>6.897) -gráfico 6-. Observamos así cómo entre el año 2001 y 2005 más de la cuarta parte de la superficie forestal afectada $(27,3 \%)$ pertenecía a pequeños municipios rurales de menos de 1.900 habitantes, 80 en total, en los cuales vive menos del 4\% de la población de Galicia. Mientras tanto, en el año 2006 el porcentaje de superficie calcinada dentro de este grupo de municipios era considerablemente inferior $(6,7 \%)$.

En el gráfico 6 se observa además como el 38\% de la superficie forestal calcinada en 2006 pertenecía a los municipios de los dos primeros cuartiles (Q1+Q2), todos ellos con menos de 3.489 habitantes $(51,3 \%$ de la superficie forestal (SF) y 11,4\% de la población de Galicia). Es una situación completamente diferente a la de los años anteriores cuando en

Gráfico 6

INDEXADO DE LOS MUNICIPIOS DE GALICIA EN FUNCIÓN DE SU POBLACIÓN Y ESTABLECIMIENTO DE CUARTILES DE REFERENCIA (Q). DENTRO DE CADA UNO DE LOS INTERVALOS INTERCUARTÍLICOS SE ANALIZAN DIVERSAS VARIABLES DEMOGRÁFICAS (POBLACIÓN) Y FORESTALES (SUPERFICIE FORESTAL, SUPERFICIE FORESTAL AFECTADA)

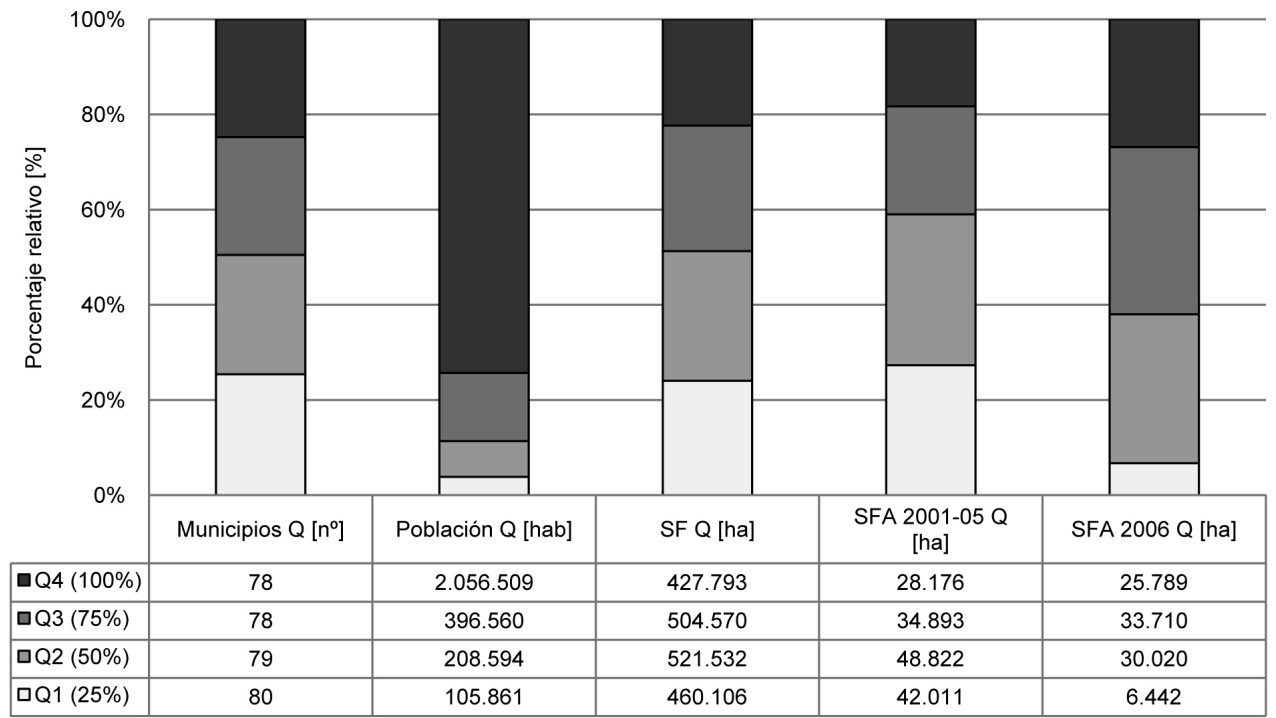

Datos de Población y Superficie Forestal del año 2006. Fuente de datos: Consellería de Medio Rural, 2007. 
este mismo grupo de municipios se concentraba el 59\% de la superficie forestal quemada. De esta forma, podemos advertir claramente que los incendios de 2006 afectaron principalmente a los municipios más poblados (Q3+Q4; 157 municipios; 41,7\% de la SF y 88,6\% de la población), a los cuales pertenecía un $62 \%$ de la superficie afectada, cuando en el período 2001-2005 este porcentaje era considerablemente inferior (41\%).

Siguiendo la misma metodología empleada anteriormente indexamos la información en función de un parámetro demográfico relativo como la densidad de población $\left(\mathrm{hab} / \mathrm{km}^{2}\right)$, obteniendo los siguientes cuartiles: Q1 (<23,5 hab/km²) y Q2 $(23,6-43,2)$, Q3 $(43,3-115,2)$ y Q4 (>115,3) -gráfico 7-. Un análisis de los datos permite observar cómo más del 40\% de la superficie calcinada en Galicia entre los años 2001 y 2005 pertenecía a municipios con densidades de población muy bajas ( $<23,5 \mathrm{hab} / \mathrm{km}^{2} ; 79$ municipios), un porcentaje muy superior al propio de la campaña de $2006(14,3 \%)$.

\section{Gráfico 7}

INDEXADO DE LOS MUNICIPIOS DE GALICIA EN FUNCIÓN DE SU DENSIDAD DE POBLACIÓN Y ESTABLECIMIENTO DE CUARTILES DE REFERENCIA (Q). DENTRO DE CADA UNO DE LOS INTERVALOS INTERCUARTÍLICOS SE ANALIZAN DIVERSAS VARIABLES DEMOGRÁFICAS (POBLACIÓN) Y FORESTALES (SUPERFICIE FORESTAL, SUPERFICIE FORESTALAFECTADA)

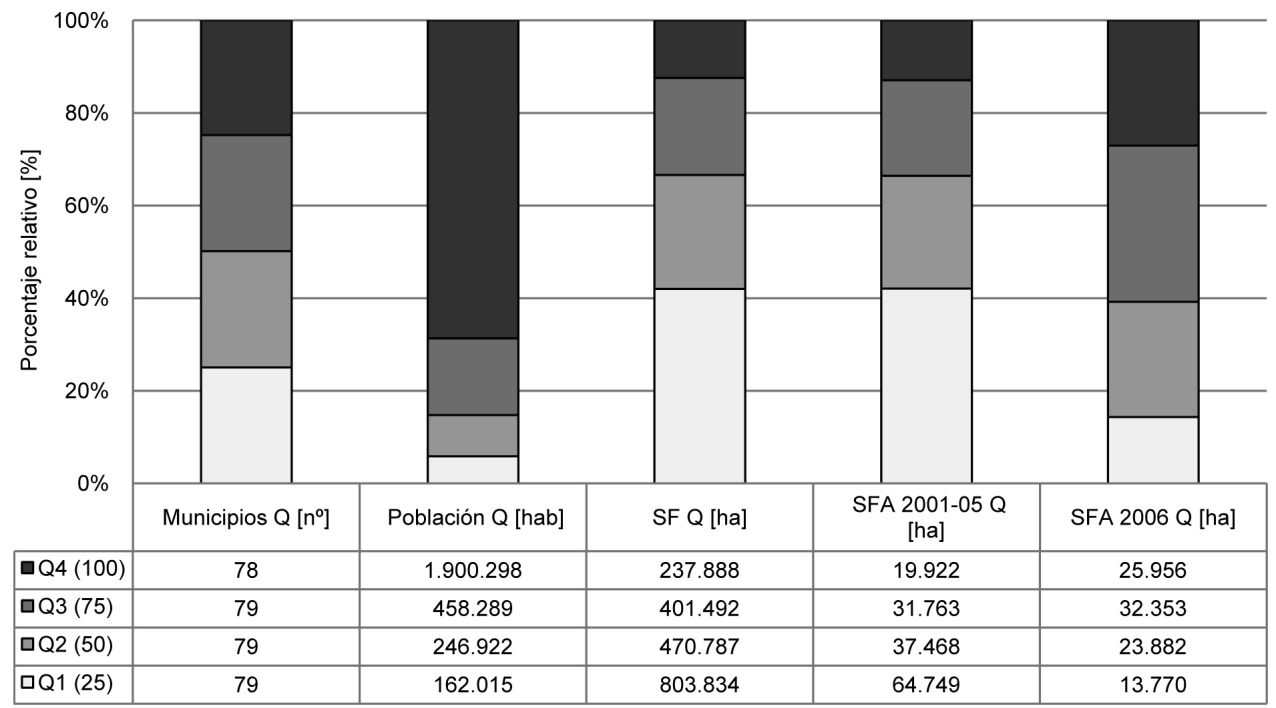

Datos de Población y Superficie Forestal del año 2006. Fuente de datos: Consellería de Medio Rural, 2007.

Normalmente, la mayor parte de la superficie forestal incendiada en Galicia $(66,4 \%)$ pertenece a municipios con densidades bajas $\left(<43,2 \mathrm{hab} / \mathrm{km}^{2}\right)$, en los cuales sólo vive el $14,8 \%$ de la población. En el año 2006 el 60,8\% de la superficie forestal afectada pertenecía a territorios con densidades medias-altas $\left(>43,2 \mathrm{hab} / \mathrm{km}^{2} ; \mathrm{Q} 3+\mathrm{Q} 4\right)$ donde vive la mayor parte de la población de Galicia (85\%). Este porcentaje es muy superior al propio de la situación habitual (2001-2005), en la que sólo se daba en este grupo de municipios un 33,6\% de la superficie incendiada. Por lo tanto, cabe pensar que si en un período normal el fenómeno 
incendiario se relaciona directamente con el abandono y la despoblación rurales, en 2006 las causas fueron otras (intención de causar un daño mayor, falta de limpieza en las áreas de vegetación periurbanas, etc.) (Balsa-Barreiro et al., 2013).

Un indexado de los municipios en función de la superficie forestal determina los siguientes cuartiles: Q1 (<2.774 ha) y Q2 (2.774,1-5.024 ha), Q3 (5.024,1-7.630 ha) y Q4 (>7.630,1 ha) -gráfico 8-. Se observa un cambio de patrón muy claro en los municipios con más extensión de superficie forestal (Q4), los cuales pasan de representar casi la mitad de la superficie calcinada en 2001-2005 (45,8\%) a únicamente un tercio en $2006(32,1 \%)$. En cuanto al número de incendios, el patrón habitual se mantiene más estable a tenor de este gráfico, no observándose diferencias muy significativas entre el año 2006 y los precedentes.

Gráfico 8

INDEXADO DE LOS MUNICIPIOS DE GALICIA EN FUNCIÓN DE SU VOLUMEN DE SUPERFICIE FORESTAL Y ESTABLECIMIENTO DE CUARTILES DE REFERENCIA (Q). DENTRO DE CADA UNO DE LOS INTERVALOS INTERCUARTÍLICOS SE ANALIZAN DIVERSAS VARIABLES DEMOGRÁFICAS (POBLACIÓN) Y FORESTALES (SUPERFICIE FORESTAL, SUPERFICIE FORESTAL AFECTADA Y NÚMERO DE INCENDIOS)

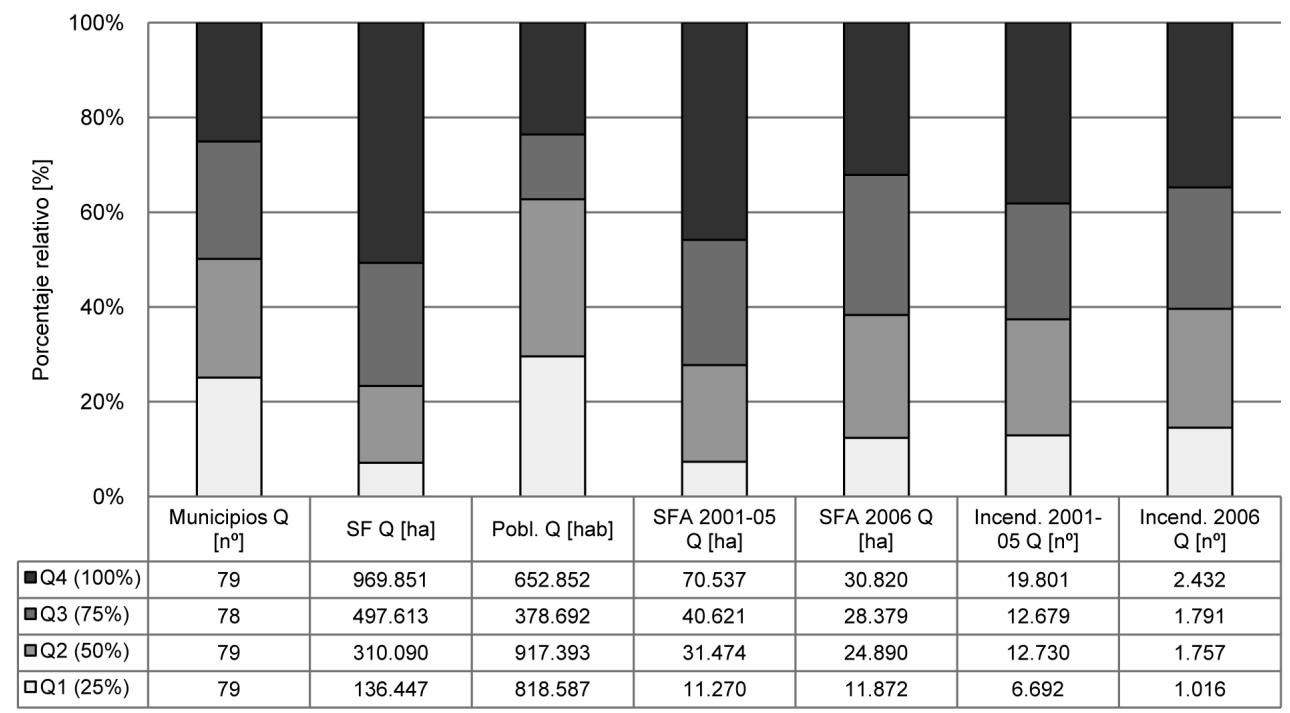

Datos de Población y Superficie Forestal del año 2006. Fuente de datos: Consellería de Medio Rural, 2007.

El análisis de la información a nivel municipal permite constatar que además de un cambio de patrón espacial a nivel provincial se produce otro a nivel intraprovincial. Este fenómeno se observa claramente en el caso de la provincia de Pontevedra, una de las más damnificadas tanto tradicionalmente como en el año 2006. En la misma se constata un cambio espacial interno, pasando de ser los municipios del interior situados en el límite con Ourense (Serra do Suído) los más afectados tradicionalmente a ser aquellos municipios próximos a la orla litoral y de carácter más urbano los más damnificados en 2006.

La concentración espacio-temporal de los incendios es causa, y a la vez consecuencia, de la magnitud de la tragedia del año 2006. La concentración espacial suponía, a priori, un fac- 
tor positivo para los servicios de extinción, aunque la tipología incendiaria propia de ese año provocó que fuera más bien una debilidad. Se produjo así un fallo en el modo de actuación de los sistemas de predicción, prevención (Baamonde, 1993), extinción y de actuación (Farrero y Villamuera, 1987; Vallejo y Camarillo, 2000), los cuales no pudieron/supieron adaptarse a la tipología incendiaria propia de ese año en contextos de urbanización difusa y proliferación de focos de fuego.

El fuerte incremento del ratio de superficie forestal afectada por incendio se debió básicamente a una mala planificación previa por parte de la Administración y a un claro fenómeno de retroalimentación del fuego (Fernández-Couto, 2006), propiciado por el retraso en la respuesta ante los pequeños incendios debido a la concentración de esfuerzos en las zonas tradicionalmente más vulnerables. Así, aunque en realidad hubiera menos incendios que otros años (-36,6\% respecto a la media de los cinco precedentes), la gran mayoría de ellos tuvieron lugar en pocos días y en espacios periurbanos en el entorno del Eje Atlántico. Ante la falta de una respuesta rápida, muchas de las pequeñas reproducciones o conatos se convertían rápidamente en incendios y, en última instancia, en grandes incendios (aquellos que afectan a una superficie superior a 500 ha.), favorecidos por unas condiciones naturales propicias para la propagación del fuego. Esto explicaría cierta incapacidad de los servicios de extinción (Martínez, 2007 y 2008).

\section{DISCUSIÓN}

El cambio en el patrón espacial es la clave para entender las trágicas consecuencias de la campaña incendiaria de 2006. Podemos establecer, una vez revisados los gráficos y figuras anteriores, que la tipología de incendios habitual en Galicia, analizada a través de la serie temporal 2001-2005, es la de fuegos en áreas rurales, mientras que la de 2006 obedeció a una tipología más urbana. De esta forma se explicaría la distribución espacial de la actividad incendiaria de 2006 y su variación respecto a los años precedentes -figuras 2, 3 y 5-. El cambio respecto al patrón tradicional puede relacionarse con estudios como el de Badia et al. (2002 y 2010) en el que diferencia en Cataluña entre tipologías de incendios periurbanos y rurales.

La dinámica de incendios tradicional en Galicia refleja que los municipios más afectados son pequeños territorios rurales de la mitad meridional. Se trata de espacios que presentan densidades de población débiles y dinámicas demográficas regresivas, debidas a claros procesos de envejecimiento demográfico y bajos índices de natalidad (figura 4.1). Presentan además una escasa incidencia de la inmigración extranjera en los últimos años, unido a que durante el siglo XX han conocido un fuerte éxodo de la población. Nos encontramos, en consecuencia, ante estructuras económicas frágiles basadas en el sector primario y en los subsidios públicos, las cuales unidas al propio declive demográfico que padecen convierten a estos municipios en poco prósperos desde el punto de vista socioproductivo.

Una dinámica poblacional regresiva repercute en el abandono efectivo de las tierras de cultivo por parte de los propietarios particulares y de las comunidades de montes vecinales, que entran en un proceso de desestructuración organizativa importante justo en zonas en las que los incendios alcanzan una mayor significación tradicionalmente, tales como los distritos forestales de Valdeorras-Trives y de Verín-Viana (E-SE de la provincia ourensana), y 


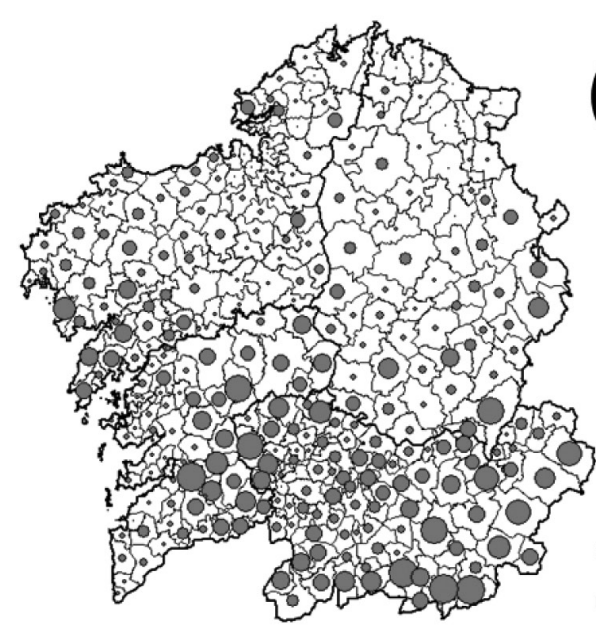

Superficie calcinada total entre los años 2001-2005

Datos por año promedio [Datos en ha calcinadas]

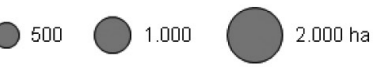

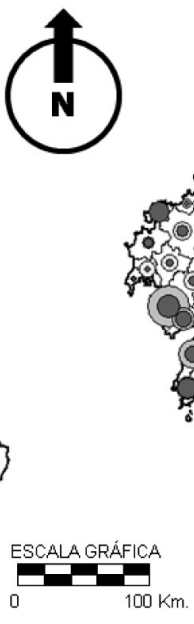

Superficie calcinada total entre los años 2001-2005 [Datos en ha calcinadas]

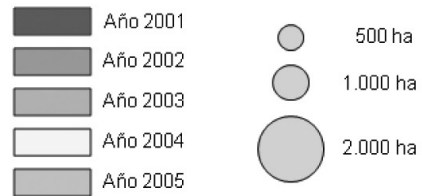

Fuente de datos: Consellería de Medio Rural, 2007.

Condado-Paradanta, en el límite entre las provincias de Ourense y Pontevedra -figura 4.2-. Por el contrario, esto no ocurre en los territorios del litoral pontevedrés del entorno del área metropolitana de Vigo, O Morrazo, Baixo Miño, Pontevedra, etc., los cuales presentan unas fórmulas de gestión comunal del monte muy eficaces.

Se inicia así un proceso de abandono acelerado que sigue las pautas propias de la teoría espacial y locacional, siendo las tierras con más dificultades de explotación las primeras en ser descuidadas. Por esta razón muchos de los municipios con más actividad incendiaria presentan una orografía montañosa, tal y como es el caso de los situados en el entorno de la Serra do Suído, en el límite entre las provincias de Pontevedra y Ourense.

Debido a estas circunstancias, la mayor parte de tierras de cultivo han pasado a ser espacios de monte entendido éste como terreno inculto (Lage, 2003). La hipótesis más probable del origen de los incendios se debe, tal como apuntan Molinero et al. (2008) para el caso de Castilla-León, al conflicto entre la Administración y el mundo rural. Choca así la dimensión productivista y postmaterialista del monte, descrita por Lage (2003), donde unos ven al monte como medio de vida para el mundo rural y otros como espacio complementario res- 


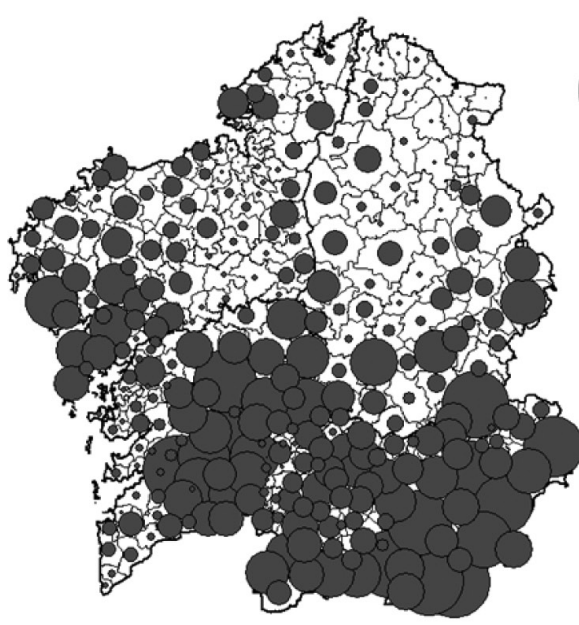

Superficie forestal calcinada en tre los añ os 2001-2005 Datos para el conjun to de la serie temporal [Datos en ha]

500 ha

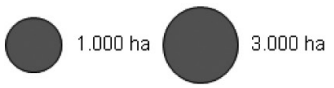

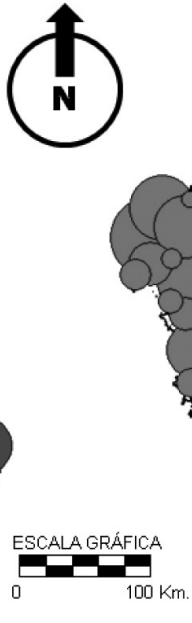

Superficie forestal calcin ada durante el año 2006 [Datos en ha]

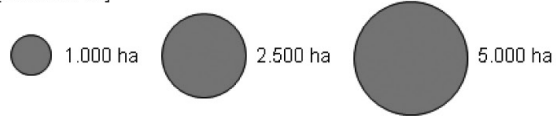

Fuente de datos: Consellería de Medio Rural, 2007.

pecto al mundo urbano, produciéndose un conflicto en el que unos ponen las normas y otros las cumplen.

En el año 2006 la actividad incendiaria se concentró, en términos cualitativos, en los municipios del litoral atlántico. La mayor parte de los incendios afectaron a territorios del eje A Coruña-Vigo (Eje Atlántico), aunque también tuvieron importantes pérdidas otros próximos, pero no pertenecientes estrictamente a este eje, como es el caso de algunos municipios de la Costa da Morte, en la provincia de A Coruña.

El principal sector afectado dentro del Eje Atlántico fue el central-meridional, determinado principalmente por el tramo que va desde Santiago de Compostela a Vigo. Aquí, la mayor parte de municipios afectados presentan altas densidades de población y dinámicas demográficas estables y/o positivas, favorecidas por su cercanía a las principales ciudades y por sus buenas comunicaciones viarias. Se trata de términos periurbanos en los que la inmigración reciente sí tuvo cierta importancia, llegando a compensar parcialmente sus niveles de crecimiento vegetativo de signo negativo. Poseen por lo general una base económica terciaria e industrial; de hecho, algunos actúan como emplazamientos de actividades industriales de desconcentración, mientras que otros se comportan como espacios residenciales, lo que en cualquier caso se traduce en una desvalorización del monte como recurso. De este modo, el motivo de la concentración de la actividad incendiaria en zonas periurbanas durante el año 2006 se relacionó probablemente con la subsidiariedad del monte respecto a otros sectores económicos y con la escasa profesionalización de los propietarios. 


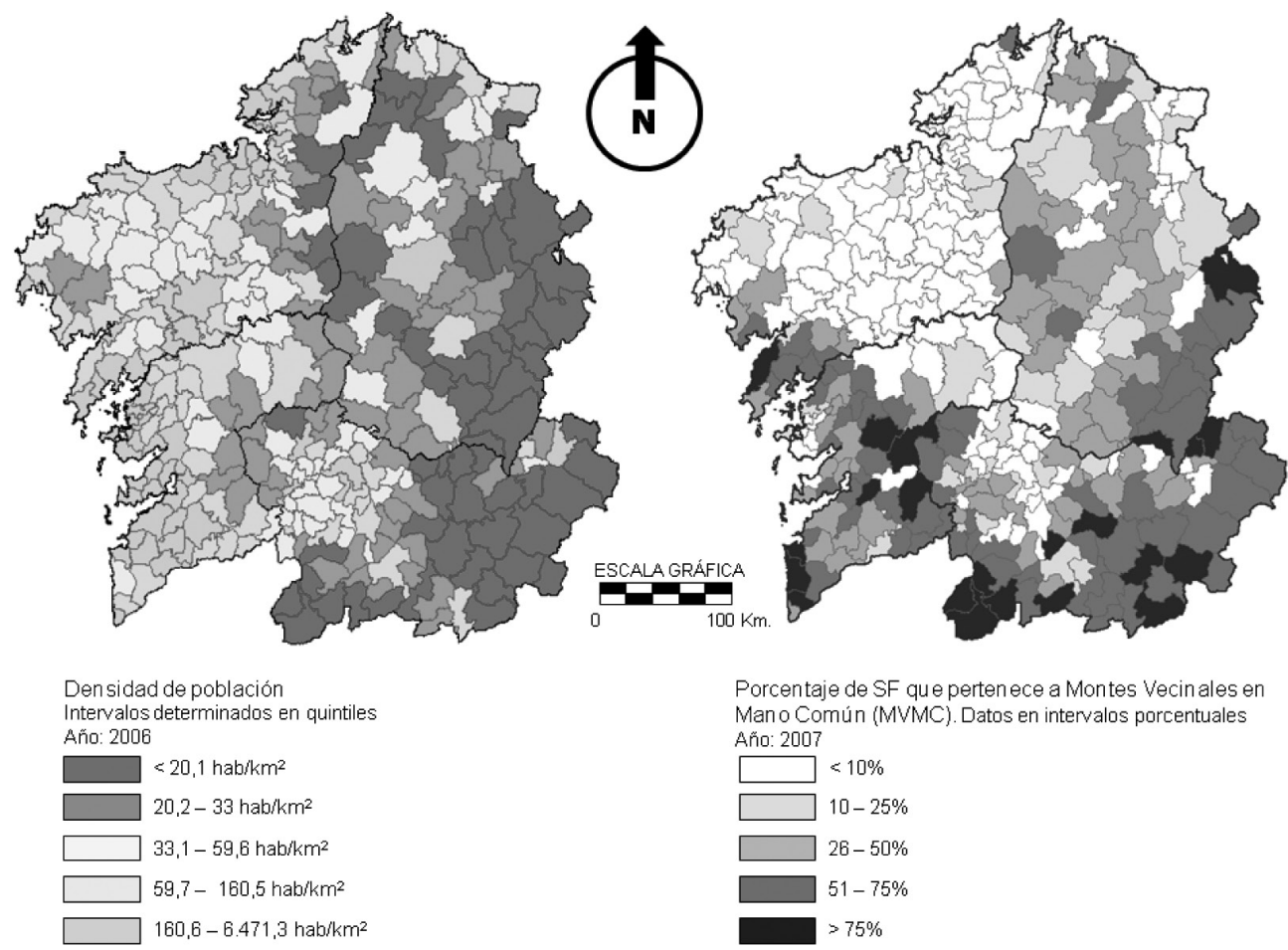

Fuente de datos: Consellería de Medio Rural, 2007.

Junto a este grupo, resultaron afectados además un segundo grupo de municipios, ubicados en enclaves de gran valor ambiental y paisajístico, como el caso de un importante sector de la Costa da Morte (Balsa-Barreiro, 2012b). Buena parte de los municipios de este sector presentan dinámicas demográficas estables o regresivas por su localización más periférica y la menor pujanza económica que muestran.

El cambio en el patrón espacial de distribución de la actividad incendiaria de 2006 es uno de los factores que explica las trágicas consecuencias derivadas. La concentración temporal de la oleada incendiaria estival en sólo 12 días supuso de por sí otro factor determinante, más aún si se tiene en cuenta el cambio en el patrón espacial. Muchos de los municipios más afectados, ubicados en el entorno del Eje Atlántico, son los más poblados y los que presentan mayores densidades. En ellos se desarrollan buena parte de las actividades económicas de Galicia, lo que supone una mayor densidad de infraestructuras y un fuerte incremento de la interacción entre fuego y actividades humanas, más aún teniendo en cuenta el crecimiento disperso del poblamiento gallego en los últimos decenios (Balsa-Barreiro, 2011). De esta forma, el cambio en el patrón espacial de la actividad incendiaria incrementó exponencial- 
Figura $5(5.1+5.2)$

COMPARACIÓN DEL VOLUMEN DE SUPERFICIE FORESTAL AFECTADA EN GALICIA EN LA SERIE 2001-05 (5.1) Y DURANTE ELAÑO 2006 (5.2). EMPLEAMOS PARA LA REPRESENTACIÓN UNA MISMA PALETA DE COLORES CON OBJETO DE PODER ESTABLECER UNA COMPARACIÓN VISUAL DIRECTA. LA METODOLOGÍA DE REPRESENTACIÓN SE BASA EN LAASIGNACIÓN DEL PESO DEL PARÁMETRO REPRESENTADO (SFA) AL CENTROIDE DE CADA UNO DE LOS MUNICIPIOS PARA, A PARTIR DE AHII Y EN BASE A UNA TRIANGULACIÓN IRREGULAR DE LA MALLA DE PUNTOS, HACER UNA INTERPOLACIÓN EXTRAPOLABLE AL CONJUNTO DE LA REGIÓN

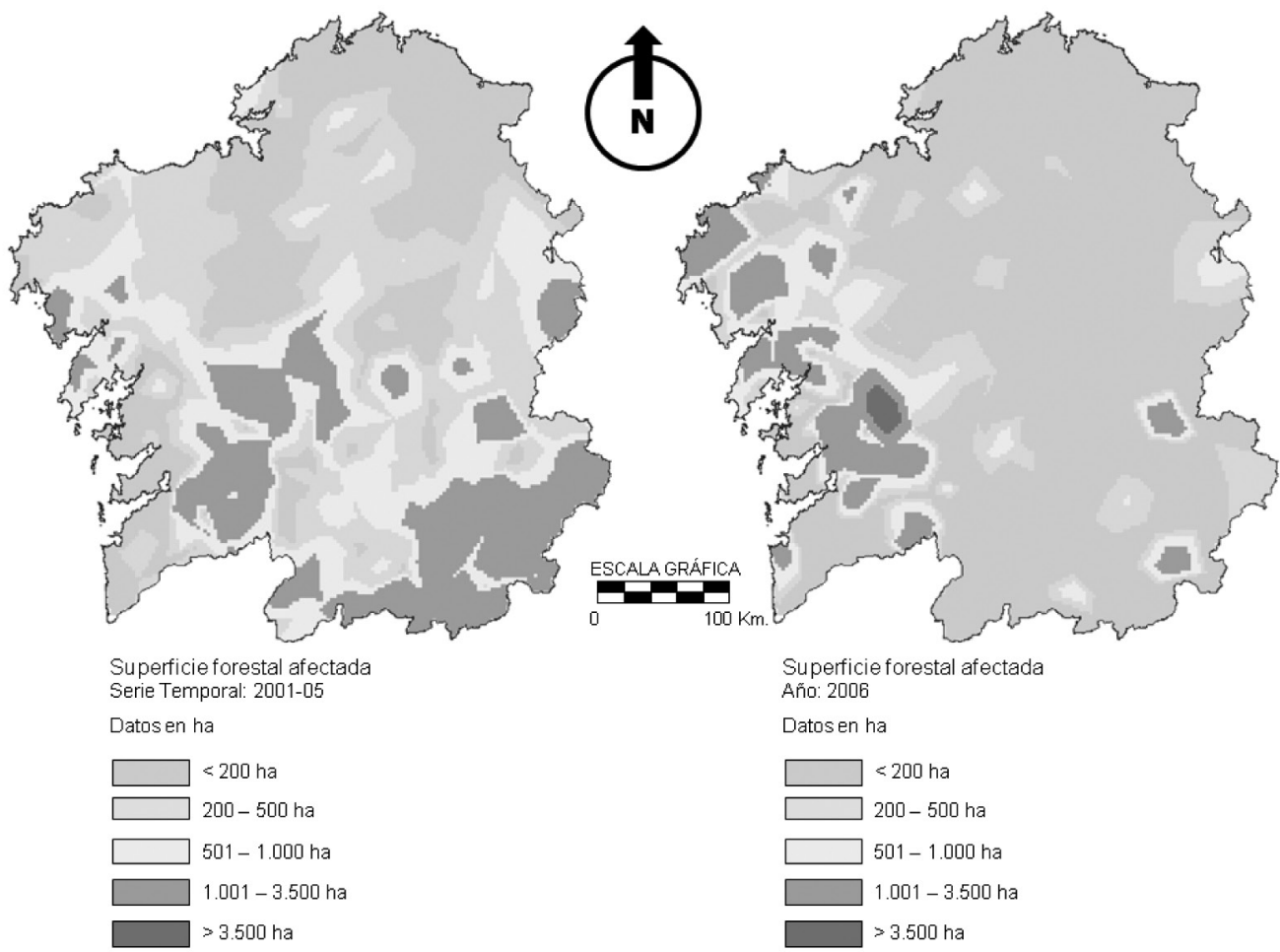

Fuente de datos: Consellería de Medio Rural, 2007.

mente el nivel de vulnerabilidad y peligro respecto a otros años, mostrándose muy limitadas las posibles respuestas por parte de los sistemas de extinción de incendios. Se produjeron de esta forma más desalojos de población, mucho más amenazada en número respecto a otros años, lo que acabó proyectando al exterior una fuerte imagen de alarma social.

El desbordamiento de la situación y el subsecuente colapso de los medios de extinción indujo a un fenómeno continuado de retroalimentación del fuego, a través del cual muchos de los incendios aparecidos pasaban a adquirir grandes dimensiones, convirtiéndose así en grandes y/o peligrosos. La consecuencia final fue la gran concentración de superficie afectada en un conjunto reducido de municipios. Así, mientras que el 75\% de la SFA entre 2001 y 2005 correspondía a un conjunto de 50 municipios con una superficie forestal total de 364.675 ha, en 2006 sólo 23 municipios con una superficie forestal total de 165.426 ha concentraron este mismo porcentaje de SFA. 
En una cuarta parte de los municipios de Galicia, 75 en total, resultó afectada más superficie forestal en sólo un año, 2006, que durante la suma de los cinco precedentes. La mayor incidencia, tanto en términos cualitativos como cuantitativos, tuvo lugar en las dos provincias occidentales, con un total de 58 municipios -tabla 1-, resultando afectada en 9 de ellos 10 veces más superficie forestal ese año 2006 respecto a los cinco años precedentes..

Tabla 1

MUNICIPIOS EN LOS QUE RESULTÓ ARRASADA MÁS SUPERFICIE FORESTAL EN EL AÑO 2006 QUE EN LA SERIE TEMPORAL DE LOS CINCO AÑOS PRECEDENTES

\begin{tabular}{|c|c|c|c|c|c|}
\hline & GALICIA & CO & LU & OU & PO \\
\hline 1-2 veces & 27 & 12 & 7 & 3 & 5 \\
\hline $2-3$ veces & 11 & 7 & 0 & 0 & 4 \\
\hline $3-5$ veces & 16 & 10 & 1 & 1 & 4 \\
\hline $5-10$ veces & 12 & 4 & 3 & 2 & 3 \\
\hline$>10$ veces & 9 & 2 & 0 & 0 & 7 \\
\hline TOTAL & 75 & & & & \\
\hline
\end{tabular}

Fuente de datos: Consellería de Medio Rural, 2007.

\section{CONCLUSIONES}

El carácter excepcional de la campaña incendiaria del año 2006 lo fue no solamente por su magnitud, sino también por una nueva tipología incendiaria, totalmente diferente a la de los años precedentes. Una de las características más representativas de la misma consistió en que la mayor parte de los fuegos tuvieron lugar en áreas periurbanas próximas a la principal arteria económica y demográfica de Galicia, el eje atlántico. Se produjo así un cambio respecto al patrón tradicional de distribución de los incendios, cuya dinámica muestra una gran incidencia en pequeños municipios rurales de la mitad meridional de Galicia (en particular la provincia de Ourense y las comarcas del interior de Pontevedra).

En el año analizado, 2006, la enorme magnitud de los incendios se asocia con este cambio en el patrón espacial, que sorprendió a los medios de extinción y a las autoridades competentes, que no pudieron articular una respuesta adecuada debido a una serie de particularidades derivadas de esta nueva dinámica: la gran concentración espacio-temporal de los incendios, la cercanía de los núcleos de población, la proximidad a enclaves turísticos de gran valor paisajístico, etc. Todos estos factores explicarían la ineficiencia de los sistemas de extinción, los cuales se vieron desbordados debido a la mayor vulnerabilidad derivada de la cercanía de las vías de comunicación, principales centros turísticos y núcleos habitados en general. Se produjo así un fenómeno de retroalimentación del fuego de nefastas consecuencias, que conllevó grandes pérdidas materiales y obligó a llevar a cabo más desalojos, lo que acabaría proyectando al exterior una imagen de caos y mala actuación política. En Galicia, una gran mayoría de los incendios son intencionados año tras año, siendo las motivaciones de los individuos que los inician muy variadas (roturaciones para 
pasto, venganzas locales, trastornos psicológicos, abaratamiento del precio de la madera, especulación del suelo, etc.). De momento, no ha sido posible establecer por qué la distribución espacial de los incendios sufrió una variación tan brusca ese año respecto a los años precedentes, aunque en un contexto de intencionalidad de los fuegos se podría apuntar que una serie de motivos programados en un determinado sector de la Galicia más poblada y urbana. La Geografía y los sistemas de interpretación de datos de contenido territorial contribuyen directamente en el análisis de catástrofes y, aguardemos, en una prevención más segura de sus efectos en el futuro.

\section{Acrónimos:}

$\begin{array}{ll}\text { ha } & \text { hectárea(s) } \\ \text { hab } & \text { habitante(s) } \\ \text { IE } & \text { índice de eficacia } \\ \text { MVMC } & \text { montes vecinales en mano común } \\ \text { NI } & \text { número de incendios } \\ \text { P } & \text { percentil } \\ \text { Q } & \text { cuartil } \\ \text { SAI } & \text { superficie arbórea incendiada } \\ \text { SF } & \text { superficie forestal } \\ \text { SFA } & \text { superficie forestal afectada } \\ \text { SI } & \text { superficie incendiada } \\ \text { SIG } & \text { sistemas de información geográfica } \\ \text { SRI } & \text { superficie rasa incendiada } \\ \text { SRPF } & \text { suelo rústico de protección forestal }\end{array}$

\section{BIBLIOGRAFÍA}

AMBROSIO, Y., PICOS, J., y VALERO, E. (2001): «Condicionantes para los aprovechamientos forestales en Galicia» en III Congreso Forestal Español, (20 - 28 de septiembre de 2001), Granada.

BAAMONDE, P. (1993): «La prevención de los incendios forestales». Revista El Campo, n 127, 179-192.

BAAMONDE, P. (2005): «Galicia fronte ao lume: ¿Historia dunha frustación?», en DÍAZFIERROS, F. y BAAMONDE, P. [coord]: Os incendios forestais en Galicia, pp. 15-28. Santiago de Compostela: Consello da Cultura Galega.

BADIA, A., PALLARÉS, M., y PIÑOL, J. (2002): «Incendios periurbanos e incendios rurales. Los casos del área metropolitana de Barcelona y de la comarca del Bages». Documents d'Análisi Geográfica, nº 41, 17-42.

BADIA, A., TULLA, A.F., y VERA, A. (2010): «Los incendios en zonas de interfase urbano forestal. La integración de nuevos elementos en el diseño de la prevención» en Scripta Nova, vol. 60, núm. 331. Universidad de Barcelona. Disponible en http://www.ub.edu/ geocrit/sn/sn-331/sn-331-60.htm 
BALSA-BARREIRO, J. (2011): «Evolución del urbanismo y de la disposición territorial del poblamiento en un municipio coruñés de interior: caso de Santa Comba (Galicia, España)». Revista de Urbanismo, nº 24, 76-118.

BALSA-BARREIRO, J. (2012a): «El modelo de gestión de la superficie forestal en Galicia y su repercusión en la crisis incendiaria de 2006». Revista Galega de Economía, vol. 21, $\mathrm{n}^{\mathrm{o}} 2,11-39$.

BALSA-BARREIRO, J. (2012b): «El desarrollo socioeconómico de Santa Comba de Xallas (A Coruña). Bases para la elaboración de un Plan Estratégico Municipal (PEDEM)», Cadernos de Traballo do IDEGA, Xeografía, no 24, 77 pp., Santiago de Compostela: IDEGA.

BALSA-BARREIRO, J., y HERMOSILLA, T. (2013): «Socio-geographic analysis of the causes of the 2006's wildfires in Galicia (Spain)». Forest Systems, vol. 22, nº 3, 497-509.

BARDAJI, M. y MOLINA, D. (1999): «Análisis comparativo interregional de los incendios forestales en la España peninsular». Revista Investigación agraria. Sistemas y recursos forestales, vol. 8, $\mathrm{n}^{\mathrm{o}} 1,151-170$.

CHAS, M.L. y MONTERO, J. (2009): «Análisis clúster de las causas de los incendios intencionados en Galicia (España)», en XIII Congreso Forestal Mundial, (18-23 de octubre de 2009), Buenos Aires, Argentina.

FARRERO, A., y VILLAMUERA, M. (1987): «Los planes de acción contra los incendios forestales». Revista MAB \& Alt Pirineu, vol. 52, n $7,1-185$.

FERNANDEZ-COUTO, T. (2006): «Los incendios forestales en Galicia». Valencia: Real Sociedad Económica de Amigos del País Valencia (RSEAPV). Universidad de Valencia. Recurso disponible en la web de la RSEAPV. <http://www.uv.es/rseapv/Anales/06/A_ Los_incendios_forestales.pdf>. [Consulta: 01 de marzo de 2011].

HERNÁNDEZ JORGE, E. (2006): Incendios forestales en España. Su impacto sobre el medio ambiente, la economía y el empleo: diagnóstico y propuestas. Madrid: Instituto Sindical de Trabajo, Ambiente y Salud (ISTAS).

LAGE, X.A. (2002): «La construcción social del bosque y la cultura forestal en Galicia». Tesis doctoral, USC, Facultad de Ciencias Económicas y Empresariales. Servicio de Publicaciones e Intercambio Científico.

LAGE, X.A. (2003): «El monte, el cambio social y la cultura forestal en Galicia». Revista de Investigaciones Políticas y Sociológicas, vol. 2, nº 1-2, 109-123.

LOIS GONZÁLEZ, R.C. (1995): Xeografía Económica I. A explotación dos recursos do territorio. Tomo 5. Xeografía de Galicia, dirigida por A. Pérez Alberti. Gran Enciclopedia Gallega. Bilbao. Págs. 306.

LOUREIRO, M. y BARRIO, M. (2009): «Valoración medioambiental, cultural y paisajística de los espacios rurales gallegos: Una perspectiva económica». A Coruña: Centro de Investigación Económica y Financiera (CIEF). Fundación Caixa Galicia.

MAREY, M.F.; RODRÍGUEZ, V. y CRECENTE, R. (2004): «Claves para comprender los usos del monte en Galicia (España) en el siglo XX», en II Simposio Iberoamericano de Gestión y Economía Forestal, (18-20 de septiembre de 2004), Barcelona.

MARTÍ, A., CABALAR, M. y GARCÍA, E. (2011): «O clima», en Mª.J. Piñeira y X.M. Santos Solla (Coord.), Xeografía de Galicia, pp. 99-130, Vigo: Ed. Xerais. 
MARTÍNEZ, E. (2007): «Grandes incendios forestales en España, ¿grandes fracasos? I. Problemática de los grandes incendios forestales». Revista Montes, $\mathrm{n}^{\circ}$ 91, 27-31.

MARTÍNEZ, E. (2008): «Grandes incendios ¿Grandes fracasos? II.- Consideraciones a tener en cuenta en la extinción de grandes incendios forestales». Revista Montes, $\mathrm{n}^{\circ}$ 93, 25-30.

MOLINERO, F.; CASCOS, C.; GARCÍA, A., y BARAJA, E., (2008): «Dinámica de los incendios forestales en Castilla y León». Boletín de la AGE, $\mathrm{n}^{\circ} 48,39-70$.

NEGREIRA DEL RÍO, F. (2004): «Estudio e identificación de épocas de peligro de incendio forestal en Galicia en los noventa». Revista Montes, $\mathrm{n}^{\circ}$ 77, 36-43.

RIGUEIRO, A., y MOSQUERA, M.R. (2005): «Outra política forestal en Galicia», en DÍAZ-FIERROS, F. y BAAMONDE, P. [coord]: Os incendios forestais en Galicia, pp. 15-28. Santiago de Compostela: Consello da Cultura Galega.

SINEIRO, F. (2005): «As causas estructurais dos incendios forestais en Galicia», en DÍAZFIERROS, F. y BAAMONDE, P. [coord]: Os incendios forestais en Galicia, pp. 77-92. Santiago de Compostela: Consello da Cultura Galega.

VALLEJO, I., y CAMARILLO, J.M. (2000): «La gestión de los riesgos naturales en el ámbito de la Protección Civil». Boletín de la AGE, nº 30, 51-68.

\section{BIBLIOGRAFÍA WEB:}

Consellería de Medio Rural, Xunta de Galicia: <http://mediorural.xunta.es> (2007).

INE (Instituto Nacional de Estadística): < http://www.ine.es/> (2010).

MMA (Ministerio de Medio Ambiente ${ }^{1}$ ): <http://www.mma.es> (2006).

1 Ahora Ministerio de Agricultura, Alimentación y Medio Ambiente (desde 2012). 